\title{
Las políticas culturales en los procesos de cambio: apuntes sobre la República Checa*
}

\author{
Winston M. Licona Calpe \\ Doctor en Economía por la Escuela Superior de Economía de Praga. \\ Catedrático de la electiva "Economía de la Cultura" en Universidades Colombianas
}

Praga, enero de 1994

\section{Resumen}

El derrumbe del llamado "sistema comunista" en los paíscs del Este es uno de los acontecimientos culturales más importantes del siglo xx, quizás el más significativo de esta centuria. En un sentido ha sido un cataclismo económico, social, político y cultural del que será un largo proceso salir exitosos, ya que no es posible "llegar al paraíso" de la noche a la mañana.

La velocidad de las transformaciones en el Este, la conocida crisis de la economía del mercado y su acutal e incipiente recuperación, pareciera que no dan tiempo de reflexionar, por ejemplo, sobre fenómenos como la cultura y sus politicas y eso que nos encontramos en el decenio mundial del desarrolio cultural (1988-1997) decretado por la UNESCO. Por ello he considerado interesante desarrollar un tema como el del presente artículo que, desde una mirada de la economia de la cultura pretende mostrar varios aspectos económicos y sociales de las políticas culturales en estos tiempos de cambio, teniendo como referente la República Checa y elaborando una comparación con las políticas culturales en condiciones de economía de mercado.

Palabras clave: política cultural, economía de la cultura, democratización cultural, democracia cultural, sociedad, mercado, socialismo.

\section{Abstract. Cultural policies in a process of change: Some comments on the Crech Republic}

The fall of the so-called "communist system" in countries East European is one of the most important cultural events of the 20th century, probably the most important one of this century. It has been an economical, social, political and ctultural cataclysm. Overcoming it successfully will be a long process since it is not possible to senter the paradise" overnight.

It may seem that the speed of transformations in the East and the well-known crisis of market oriented economy which is at present incipiently recovering do not give us enough time to reflect on, for example, phenomena such as Culture and cultural policies, although UNESCO declared this decade World-Wide decade of cultural development (1988-1997). Therefore, I tackle the subject of this article trying - from a point of view of cultural economy - to point out different economic and social aspects of cultural policies in the present changing times. The point of reference is the Czech Republic, on which

* El presente artículo forma parte de la tesis doctoral: Apuntes económicos y sociales sobre las politicas culturales de la Reptiblica Checa y algunos paises con economia de mercado, presenrada en la Escuela Superior de Economía de Praga. 
case I have elaborated a comparison of cultural policies in conditions of market oriented economy.

Key words: cultural policies, culture economy, cultural democratization, cultural democracy, society, market, socialism.

\section{Sumario}

El concepto de políticas culturafes en el socialismo

La economía pública de la cultura en el socialismo de la

República de Checoslovaquia

Datos comparativos de dos sectores culturales

La cultura en la nueva constitución de la República Checa
Nuevos criterios de políticas culturales en la República Checa

Economia de la cultura en

la nueva economía de la República Checa

Perspectivas de las políticas culturales en la República Checa

Bibliograffa

Cuando ya tenia respuestas a la vida. me cambiaron las preguntas.

Anónimo

\section{El concepto de políticas culturales en el socialismo}

El modelo socialista de políticas culturales en la República Checa no fue sólo un hecho de ideologización de la cultura, sino también de determinismo conceptual en la definición de sus objetivos y estrategias de acción. Antes de entrar en su análisis, una aclaración sobre la ideologización de la cultura:

Resulta mal infundado concebir la ideologización en las políticas culturales sólo como una "enfermedad crónica del socialismo", porque una cosa es que el socialismo la haya declarado abiertamente, y orra que el capitalismo haciendo uso de ella en forma velada niegue generalmente sus pretensiones ideologicas en la cultura. Lo cierto es que cada sistema ha hecho de la gestion cultural un accionar ideologico acorde con las características de su estructura. "Dentro de todos los países, el objetivo mayor de una planificación cultural es la de poner en funcionamiento una cultura conforme a la elección de la sociedad y el poder, porque no puede aceptar la promoción de acciones contrarias y externas a su ideología, si lo hace como generalmente ocurre, es porque ellas son impuestas por razones del equilibrio de fuerzas sociales en presencian (UNESCO, 1974: 34).

Como afirma Galbraith, "La constante más inmediata es que las personas y comunidades favorecidas por su acción económica, social y política, atribuyen virtudes sociales y permanencia política a aquello de lo que disfrutan. Esta atribución se reivindica incluso ante la abrumadora evidencia en sentido contrario. Las creencias de los privilegiados se ponen al servicio de la causa de la satis- 
facción continua y se acomodan de modo similar las ideas económicas y políticas del momento. Existe un ávido mercado político para lo que complace y tranquiliza. Los que pueder abastecer este mercado y recoger la recompensa correspondiente en dinero y aplausos, están facilmente disponibles" (Galbraith, 1992: 14).

El fenómeno de la guerra fría entre los dos sistemas y la pugna paranoica del uno hacia el otro trajo como consecuencia, entre otras, el reforzamiento de unas estrategias de acción cultural. El núcleo de cada estrategia era la conceptualización que cada sistema hacía en defensa de sí mismo y descalificación del otro. ¿A esto cómo lo llamaríamos? ¿Ideología? Sí. Era y es la cosmovisión de dos mundos enfrentados. La propaganda de uno y otro bando estaba lejos del lenguaje de la inocencia. Los análisis que al respecto se hacían desde cada disciplina como la economía, filosofía, sociología, etc., no comportaban ninguna neutralidad en materia de juicios de valor. $Y$, ja esto cómo lo denominaríamos? "La ideología puede considerarse como una teoría abstracta que pretende tener aplicabilidad general, no total" (Katouzian, 1982: 188). Es decir, no se trata de simples motivaciones sesgadas, sino de cosmovisiones que pueden ser diferentes y sujetas a crítica y/o rechazo, influidas además por la historia personal y social ${ }^{1}$.

Es evidente, entonces, que la cultura y sus políticas sólo pueden articularse con el concurso de una ideología que las estructura y confiere sentido a cada uno de sus elementos, pero con la imposibilidad de ser reducible a simple ideología. Es evidente también que la cultura como sujeto de políticas es un proceso orientado por definición. Pero, a diferencia del mundo occidental, el pasado campo socialista asumió un determinismo conceptual en la cultura.

1. Por ejemplo, en el caso de la ciencia económica, como afirma Katouzian, la ideología tiene relación directa con las necesidades y exigenciaas, con la organización social existente, con los medios acumulados a su disposición y con el fondo de conocimientos del que se parte (cosas todas ellas en su mayoria, sino en su totalidad, finitas). El fondo de conocimiento descubrible ni es infinito ni aleatorio: posibilitan un avance limitado y relevante desde el punto de vista del entorno socioambiental del conocimiento y en tanto esos límites se amplíen y las necesidades se alteren, así lo harán los límites y las direcciones de avance del conocimiento.

[...] Los mercantilistas definieron el beneficio como un excedente monetario - las diferencias entre los precios de compra y los de venta - porque, dado su entorno y organización socioeconomica, el beneficio era, sobre rodo, un rendimiento sobre el capital mercantil. Sus teorias y observaciones eran simples; así lo eran también las estructuras económicas cuyos problemas discutian. Los economistas clásicos se enfrentaron a los problemas de una economía en desarrollo, de una sociedad en proceso de industrialización. En consecuencia, investigaton la determinación de los precios relativos, distribución de la tenta, las causas del crecimiento poblacional, condiciones de progreso económico. Los primeros neoclásicos florecieron en las sociedades industriales maduras, dominados por una pequeña producción a pequeña escala, con una intervención pública limitada y un crecimiento lento; por ello estudiaron la estática microeconómica. Los neoclásicos contemporáneos y los economistas keynesianos prestaron una gran atención a los problemas macroeconómicos y dinámicos por similares razones socioambientales. Otra cuesción es la de si esos economistas (pasados y actuales) obraron bien o mal en la elección de los mérodos apropiados. (ver H. Katouzian, Ideologia y Metodo en Economia. Madrid: Ediciones H. Blume, p. 190). 
El determinismo conceptual en las políticas culturales de la República de Checoslovaquia en el régimen socialista se puede observar en los documentos oficiales de información cultural o en los análisis de su desarrollo. En la misma Constitución del año 1960 en su Arr. 16, decía: "Toda la política cultural en Checoslovaquia, el desarrollo de la educación, la instrucción y la enseñanza están regidos por el espíritu científico y la visión del mundo del marxismo-leninismo y en estrecha relación con la vida y el trabajo del pueblo" (Flegel, 1974: 49). La inclusión del marxismo-leninismo como «doctrina" inscrita en la Constitución, "suprimión por sí misma la pluralidad teórica y cultural de la sociedad; no dando espacio a la nación para una libertad competitiva en términos del libre juego de ideas y creaciones culturales que entraña el desarrollo cultural de la sociedad. Además, desconoció en la realidad los elementos constiturivos de la cultura, sobre todo el nivel uíntimo" o de las significaciones y sentidos que se tejen en el universo micro y/o cotidiano de los individuos.

Aún comprendiendo las circunstancias históricas de la República de Checoslovaquia para el adelanto de investigaciones, sobre todo en el sector cultural, sorprende el dogmatismo y reduccionismo teórico de los análisis, cuando es justamente en el sector de la cultura donde los esquemas se cuestionan y resulta casi imposible aferrarse a una sola teoría. Es como si en el marxismo-leninismo hubiera concluido el desarrollo del conocimiento científico. Por ejemplo: «Para la conceptualización de la cultura y la delimitación del objeto de la prognosis hemos obrado a partir del punto de vista de la filosofía marxista-leninista, de la teoría de la cultura marxista-leninista, de la sociología marxista-leninista y de la economía marxista-leninista” (Ceip, 1986: 25 ).

Lo grave del reduccionismo conceptual no fue la simple defensa de un punto de vista; sino la manipulación, la exclusión, el autoritarismo y el excesivo centralismo que generó. Así se fundamentó el estalinismo. El estalinismo como sistema burocrático y policial de dominio absoluto, se funda sobre la idea de la manipulación general de los hombres y las cosas, del hombre y la naturaleza, de las ideas y los sentimientos, de los vivos y los muertos. Base o punto de partida de una oscura concepción del hombre y el mundo, de las cosas y de la realidad, de la historia y su naturaleza y de la verdad y el tiempo. La dialéctica no es un simple método y mucho menos un conjunto de reglas; no es una simple totalización, tampoco se limita a la realidad histórico-social: a su vez nace de un pensamiento crítico desmitificante y, por tanto, está más próxima a la sabiduría que a la destreza de la aplicación de ciertas reglas del pensamiento (Kosik, 1988: 215). En una entrevista A. Dubcek afirmaba: "La crítica del pasado no se debía transformar en apología de todo lo que poseyera una "etiqueta socialista", el florecimiento de dogmatismos, la rigidez y la estaticidad empeñada como estabilidad, instaló el conformismo, el sectarismo del mando superior y la aceptación mecánica de modelos" (Dubcek, 1988: 166). 


\section{La economía pública de Ia cultura en el socialismo de la República de Checoslovaquia}

A pesar de que algunos sectores consideran que la intervención del Estado en los asuntos culturales está bajo sospecha, es indudable la necesidad de su mediación, no solo en la búsqueda de equilibrar los procesos de acumulación de capital en sentido económico, sino de satisfacer las necesidades y exigencias sociales, entre otras las culturales. Aún siendo un tanto superficial en el tema, la economía pública de la cultura se refiere a la conceptualización y gestión que desde la esfeta del Estado se ha emprendido en el sector cultural, bajo un punto de vista de política económica y social para la generación, captación, uso y distribución de recursos monetarios, físicos y humanos desde el sector estatal hacia el desarrollo cultural e involucrando al sector privado y a la sociedad civil en general.

Un concepto utilizado en tiempos del socialismo en la República de Checoslovaquia - al igual que en la mayoría de naciones del mundo-, fue considerar la economía y la cultura como partes de una "totalidad". Sin embargo, tanto teórica como prácticamente, la cultura fue clasificada como parte de la esfera no productiva $a^{2}$. Criterio "clásico" también compartido por no pocos Estados, independientemente del tipo de sistema.

Considero que esta apreciación perdió de vista un elemento muy importante de la reflexión económica para el sector de la cultura; esto es, el mercado, punto donde se cruza la cultura y la estructura social. Además, una de las características de la modernidad y posmodemidad es que la producción cultural ha generado un proceso de conversión hacia lo que hoy se denomina la industria cultural, cuya estructura ha asimilado todos los mecanismos de la dinámica económica en general. Se puede decir que subyace una contradicción; máxime cuando la cultura fue definida corno parte de la economía nacional (Ceip, 1986: 37).

El criterio de la economía de la cultura como "esfera no productiva», originó consecuencias económicas adversas y causó una disparidad entre el rol social de la cultura y la creación de condiciones materiales para su desarrollo. El resultado natural de esta actitud hacia la economía de la cultura es la relación de la cultura con el ingreso nacional, no sólo por los complicados aspectos metodológicos, sino por la orientación puramente supervisora de la maquinaria económica en el uso del ingreso nacional en este campo, sin mayores incentivos a la eficacia del trabajo realizado. En consecuencia, el uso de instrumentos económicos individuales en el campo de la cultura (costos de la actividad cultural, precios, ingresos, niveles salariales) fueron de naturaleza formal, sin cumplir una función progresiva y estimuladora. Esta funcional desventaja estuvo agravada porque a pesar que la cultura fue en parte autosostenida, en la planificación se consideró parte del consumo social, origi-

2. Martin Ceip y D. Kaderobková en su libro Desarrollo del sector de la cultura, plantean este criterio sin desarrollarlo. Praga: Departamento para Investigación Cultural, p. 25, 1986. 
nando efectos negativos en la inversión, los salarios y los precios políticos en el sector.

El rol de la cultura en el proceso educacional no es puramente de naturaleza de consumo o por analogía un consumo de gastos de inversión. El significado de este gasto debía tener presente que el sujeto de la actividad cultural es el hombre, el más importante factor del desarrollo de la sociedad en general. El recurrente carácter del consumo y el efecto de la actividad cultural sobre la futerza creadora del hombre, justifican describir los gastos sobre la actividad cultural como inversion en el factor humano (Marek, 1977: 59).

\subsection{La planificación cultural en la República de Checoslovaquia}

Aunque en este punto sea puramente descriptivo, hemos de reconocer que el proceso de planificación cultural en la República de Checoslovaquia durante el régimen socialista, independientemente de errores y de su determinismo conceptual, fue considerado por expertos de la UNESCO como uno de los modelos más coherentes, por cuanto los objetivos expuestos constituían una base explícita y clara en armonía con las políticas culturales promovidasí. Se afirma además que los planificadores culturales en Checoslovaquia insistían en la necesidad de una exploración de largo tiempo, a fin de revelar los elementos de la evolución del desarrollo cultural y descubrir los factores que lo determinan. Precisamente, la Conferencia de Helsinki lo recomendaba 5 . Además, siempre hubo una intención de estudiar la demanda cultural en constante interdependencia con la demanda económica y social. Por ello es posible considerar que existía una visión global que no se quedaba en una apreciación sectorial y particular. A esta visión global correspondía una reflexión sobre las relaciones de la acción cultural con otros sectores como el educativo y el de acción social. Hubo también una constante preocupación por las condiciones de organización y gestión de los asuntos culturales, los problemas presuputestales, la relación entre medios y objetivos, descentralización y centros de decisión. Estudios, por tanto, sobre la economía de la cultura, que aportaron muchos elementos a las conferencias internacionales sobre políticas culturales.

La utilización de un método de planificación pertinente no permitió evitar ciertas contradicciones que expresaron muchos vacíos, entre los cuales se destacan:

3. En el interesante trabajo de la Ing. Bojka Hamernilová, encontramos diferentes aspectos que demuestran las limitaciones de reducir la culcura a la esfera no productiva, en tanto la cultura juega un papel preponderante, sino definitivo en toda la estructuración de la sociedad, en sus relaciones económicas, politicas, etc. (Ver el trabajo de la autora Ekonomika nevyrobnt sferysocialne ekonomické aspekty kultury. Esfera Económica no productiva: Aspectos económicos y sociales de la cultura. Praga: SNTL, 1989, p. 38-54).

4. Ver UNESCO, Cuadernos de desarrollo cultural Thenevin Pierre: «Por tna merodologia de la planificación cultural $n$. París, 1974 .

5. Ver UNESCO, Comision National Finnish. "The development of cultural policies in Europen. Publication, núm. 21. Helsinki. 1980, p. 25. 
- Las necesidades culturales de los jóvenes.

- La existencia de una burocracia pesada a falta de estudios e insuficiencia de especialistas.

- La complejidad de la existencia, entonces, de dos culturas: Checa y Eslovaca.

- Las condiciones de vida que producían dificultades en el desarrollo cultural de los individuos: la vivienda urbana, la parcelación del trabajo, los mass media y el consumo cultural pasivo.

- Las contradicciones entre los deseos de prácticas culturales individuales (consumo cultural monetario en bienes de equipamiento) y el establecimiento de prácticas sociales.

- La contradicción entre profesionalización de la cultura y la participación ciudadana.

- La contradicción entre planificación y libertad ${ }^{6}$.

\subsection{Los precios en el sector cultural en el socialismo checo}

Por principio, la definición de precios políticos, no sólo en el sector cultural, fue una característica de mayor uso en el sistema socialista. Esto suponía la redistribución social de los beneficios económicos a manera de subsidios.

En el sector cultural la definición de los precios es una función de la politica cultural. En el sistema socialista - afirmaba un planificador-, se debían respetar los precios políticos de Estado, porque las metas de las políticas culturales eran crear las condiciones para acercar necesidades e intereses de los individuos y la sociedad. Por tanto, los precios no podían convertise en factor limitante. «Los precios de los bienes y servicios culturales, aunque son uno de los criterios de elección del consumidor potencial, no deben ser un factor limitante para el consumo. Elevar los precios en estos, es limitar la manera socialista de combinación del fondo social y las necesidades personales" (Ceip, 1986: 108).

Existe una contradicción inevitable, por cuanto un objetivo permanente en el sector cultural es ampliar los servicios, y una manera de hacerlo puede ser mediante el incremento de los precios, pero si esto se hace, es posible la disminución del acceso a los servicios. O sea que, mantener precios bajos en el sector cultural fue una necesidad pensando en la democratización de la cultura, un elemento esencial de la gestión pública en el sector. «La política de precios en el sector cultural convierte principios generales válidos a nivel de todo el complejo económico nacional, a condiciones específicas y concretas del sector cultural, como el marco de principios en completo acuerdo con las metas de la política cultural. La problemática de los precios tiene no sólo un aspecto económico, sino también cultural, político y social" (Hamerniková, 1989: 81).

Los precios políticos en el sector cultural en la República de Checoslovaquia cumplieron una función altamente redistributiva, por cuanto no representaron los costos reales que implicaban las inversiones, los gastos de manteni-

6. Ver UNESCO, Pierre Thenevin. París, 1980, p. 32. 
miento y financiación de todas las acciones culturales. Resulta entonces evidente que los precios posibilitaban a los ciudadanos un frecuente acceso a los bienes y servicios culturales. Dicho acceso podría considerarse como parte de los ingresos de la población, invertidos en la satisfacción de algunas necesidades culturales? ${ }^{7}$.

Desde el punto de vista de la economía pública, estos precios pueden denominarse precios justos, o sea aquellos que se establecen considerando un efecto sobre la redistribución de la renta. Existe polémica al respecto, unos afirman que: «los subsidios al consumo de bienes, representan modos particularmente ineficientes de redistribución de renta [...] El mejor modo de mejorar la situación de un individuo es darle una cantidad apropiada de dinero [... ]" (Stiglitz, 1988: 592),

\section{Datos comparativos de dos sectores culturales}

\subsection{Algunos datos sobre el sector cinematográfico}

Tabla 1. Salas de cine en algunos países europeos

\begin{tabular}{lllllllll}
\hline País & $1945-47$ & 1955 & 1967 & 1983 & 1987 & 1988 & 1989 & 1990 \\
\hline República Checa & 1.650 & - & 3.612 & 2.866 & - & - & 2.796 & 2.666 \\
España & - & - & - & - & - & 1.882 & 1.802 & 1.773 \\
Gran Bretaña & 4.700 & - & - & 1.562 & - & - & - & - \\
Alemania & & 6.000 & - & 3.854 & 3.252 & - & 3.216 & - \\
\hline
\end{tabular}

Fuente: Politicas culturales en CHSFR, 1977. Statistisches Jahtbuch BRD, 1991. Boletin informativo cinematográfico, Espafia 1991. El cine y el Estada. Ministerio de Cultura de Espafia, 1982.

De la tabla anterior podemos deducir varios aspectos:

- El proceso paulatino del cierre de salas de cine en los diferentes países producto de la crisis cinematográfica revelada desde los años setenta. Diversas han sido las causas aducidas: la disminución de la asistencia a las salas de cine por los adelantos técnicos en la televisión y el surgimiento del vídeo, el auge de espectáculos masivos como el futbol, los grandes conciertos, la competencia voraz por los mercados entre el cine europeo y la fuerza del cine norteamericano, país en el cual las salas de cine no llegan a la mitad de las qute posee Europa unida ${ }^{8}$.

7. Una duda que ha quedado sin respuesta es: ¿̨a población reconoció esa posibilidad brindada como un hecho real de su vida cotidiana? Podria pensarse que definitivamente más puede la liberrad de elección a precios más altos que la manipulación a bajo costo...

8. Ver El cine y el Estado. Ministerio de Cultura de España, 1982, p. 29. (Colección Cultura y Comunicación, núm. 20). 
- La capacidad instalada o infraestructura en salas de cine de Checoslovaquia es mucho mayor que en los países mencionados, no sólo si se tiene en cuenta el número de salas, sino la relación con el volumen de población (República Checa $=15,6$ millones. España $=39$ millones. Gran Bretaña = 57 millones. Alemania $=60$ millones).

Tabla 2. Asistencia al cine en algunos países de Europa (en millones de espectadores)

\begin{tabular}{lcccccccc}
\hline País & $1945-47$ & 1955 & 1967 & 1983 & 1987 & 1988 & 1989 & 1990 \\
\hline República Checa & 54,2 & & 118,6 & 85,8 & 78 & 70,6 & 50 & \\
Gran Bretaña & 1.462 & & & 107 & & & & \\
Alemania & & 866 & & 124,2 & 110 & 101,6 & & \\
Francia & & 440 & 240 & 168 & & & & \\
Italia & & 820 & & 373 & & & & \\
España & & & 393,1 & 211,9 & 141,1 & 78,1 & 78,5 & 79,1 \\
Grecia & & & & 39 & & & & \\
\hline
\end{tabular}

Fuente: Ceip, Kaderabková, Rosvoj Odvetví Kultury, 1977. Statitisches Jahrbuch BDR, 1991. Boletín Cinematográftco de España, 1991. El cine y el Estado. Ministerio de Cultura de España, 1982.

Tabla 3. Frecuencia de asistencia al cine (promedio por persona y año)

\begin{tabular}{lllll}
\hline País & 1977 & 1981 & 1989 & 1990 \\
\hline República Checa & 5,7 & 5,3 & 5 & 3,57 \\
Francia & 3,2 & 3,5 & & \\
Alemania & 2 & 2,3 & 1,68 & \\
Gran Bretaña & 1,9 & 1,5 & & \\
España & 5,6 & 4,6 & 2 & 2 \\
\hline
\end{tabular}

Futente: Ceip, Kaderabková, Rosvoj Odvetví Kultury, p. 58. Complementado por el autor de este זrabajo.

Es evidente la mayor frecuencia de asistencia al cine de una persona en la República de Checoslovaquia. Se argumenta que debido a un menor volumen de receptores de television en los hogares los habitantes frecuentaban más las salas de cine, también por los precios más asequibles. Esto es cierto, pero no menos cierta es la existencia de una cultura cinematográfica que hace de la República Checa un mercado potencial, ahora controlado en mayor medida por el cine norteamericano como una novedad de los cambios y con precios más ajustados a los costes y las utilidades de los empresarios.

\subsection{Algunos datos sobre el sector teatral}

El teatro es una actividad difícilmente rentable, por lo tanto en todos los países es estimulada por los poderes públicos, puesto que es un medio fundamental de la comunicación cultural. Algunos datos: 
Tabla 4. Número de salas de teatro

\begin{tabular}{lccll}
\hline País & 1967 & 1989 & 1990 & 1991 \\
\hline República Checa & 85 & 88 & 98 & 113 \\
Alemania & 101 & 217 & - & - \\
España* & - & 60 & - & - \\
\hline
\end{tabular}

Fuentes: Statistická Rocenka Kulrury, 1989-90-91. Statistisches Jahrouch BDR1, 991. Espafia, Boletín informativo, 1992.* Exciuidas no comerciales que son numerosas.

Tabla 5. Asistencia al teatro (en millones de espectadores)

\begin{tabular}{llcll}
\hline País & 1967 & 1989 & 1990 & 1991 \\
\hline República Checa & 10,2 & 7,8 & 7,2 & 5,9 \\
Alemania & 12,3 & 15,2 & - & - \\
Espafia* & - & 3,6 & - & - \\
\hline
\end{tabular}

Fuentes: Ver tabla 4.

Si se observan de manera detallada las anteriores tablas, se deduce que la actividad teatral en la República Checa es mayor en relación con los países mencionados tomando como base el número de habitantes. La actividad teatral a nivel de apoyo estatal recibe una suma significativa en diversos países de Europa: República Checa (1988) = 611,5 millones de cotonas. España (1988) $=670,5$ millones de pesetas. Francia $(1986)=672$ millones de francos. Italia $(1987)=123,5$ millones de liras. Alemania $(1987)=2.708$ millones DM, en donde el mayor aporte lo realizan los municipios con 1.603 millones de DM, seguidos por los länder con 1.090 millones y el aporte casi insignificante del Federal con 15 millones DM. La mayor parte de las subvenciones estan destinadas a pagar costos salariales que, por lo general, superan el $70 \%$ de los recursos (Cataluńa, 1991: 219).

\subsection{Algunos datos sueltos}

En cuanto a los precios de entrada a los museos, Gran Bretaña se constituye como una excepción en Europa al brindar en Londres el acceso gratuito a los grandes museos como el British Museum, la National Gallery o la Tate Gallery. En el resto de países, incluido EEUU, los precios de entrada oscilan entre 5 y 6 dólares, esto contrasta con los precios en la República Checa que no llegan a I dólar. Esta comparación sólo puede ser objetiva en relación con los niveles salariales y los gastos por persona en actividades culturales.

En resumen, las actividades culturales tradicionales en la República Checa cuentan con una demanda potencial elevada, subsidiadas por el Estado de manera casi completa en el antiguo régimen. La existencia de una infraestructura muy amplia y diversa suponía mayores gastos de mantenimiento que 
Tabla 6. Número de usuarios de biblioteca (en millones de lectores)

\begin{tabular}{ll}
\hline País & Año 1990 \\
\hline República Checa & 3,264 \\
España & 3,388 \\
Alemania & 6,567 \\
\hline
\end{tabular}

Fuente: Ver tabla 4 .

Tabla 7. Número de visitantes a los museos (en millones de personas)

\begin{tabular}{ll}
\hline País & Año 1989 \\
\hline República Checa & 15,803 \\
Espafia & 18,434 \\
Alemania & 70,035 \\
\hline
\end{tabular}

Fuente: Ver tabla 4.

de inversión. El hecho de poseer una capacidad instalada sólida, indudablemente la convierte en un punto de interés para los inversores privados, al tiempo que exige una responsabilidad del Estado y de la sociedad civil para acciones o políticas culturales de conjunto. La dificultad en la consecución de información ha impedido hacer una prospección más amplia acerca de diferentes expresiones culturales. A pesar de las insistentes recomendaciones de todas las conferencias internacionales en materia cultural, apoyadas por la UNESCO, para que se pueda intercambiar una información estadística global, sigue siendo difícil acceder a los datos actualizados del sector cultural en diferentes países.

\section{La cultura en la nueva constitución de la República Checa}

Con la nueva Constitución aprobada el 16 de diciembre de 1992, podemos decir que la República Checa ingresó formal y oficialmente en el "Club" de países con economía de mercado. En materia de cultura, aunque no particulariza tanto como otras Constituciones, recoge los postulados más generales y característicos de los países con economía de mercado (libertad y promoción cultural). El preámbulo dice:

La República Checa, como parte de la familia de democracias europeas y mundiales conjuntamente decidjdas a salvaguardar y desarrollar las heredadas riquezas naturales, culturales, materiales y espirituales", resuelve:

9. Ver: Sbirka Zakonu Ceské Republiky. Racnik, 1993. Castka 1. Ustava Ceske Republiky, rozesláná 28 de diciembre de 1992. Ser. 5. 
Artículo 15 de capítulo II:

(2) Se asegura la libertad de investigación científica y de creación artística.

Artículo 34 de capítulo IV:

Están protegidos por la ley, el derecho de creación de los creadores de actividades espirituales.

(2) Se asegura el derecho a la apropiación de la riqueza cultural; condicionado por lo que al respecto establezca la ley (Sbirka, 1993: 22).

Como las modernas Constituciones, incorpora un elemento de reciente preocupación en el mundo, el del medio ambiente, cuando dice en el artículo 35:

(1) Cada cual tiene derecho a un medio ambiente saludable.

(2) Cada cual tiene derecho a informaciones completas y actuales acerca del estado del medio ambiente y los recursos naturales.

(3) Nadie en la ejecución de sus derechos debe amenazar ni perjudicar el medio ambiente, los recursos naturales, las riquezas secundarias de la naturaleza y los monumentos (reliquias) culturales sobre la medida establecida por la ley (Sbirka, 1993: 22).

Queda así, en materia constitucional, saldado el determinismo conceptual de la hoy vieja Constitución Socialista que marcó el rumbo de la política cultural durante 44 años. Tiempo corto en la historia, pero suficiente para mostrar la ineficiencia y artificialidad de pretender condicionar la cultura bajo un esquema. Viene ahora un proceso necesario de la democracia: la reglamentación de la Constitución que supone leyes y decretos, para la cual es necesario tener en cuenta las opiniones de los actores sociales. Este es un aspecto central de la democracia.

\section{Nuevos criterios de políticas culturales en la República Checa}

El barómetro de la libertad es la cultura. En efecto, el manifiesto de Foro Cívico ${ }^{10}$ bajo el título "Esto es lo que queremos", en 1989 incluia en su punto final el siguiente criterio que habría de iluminar las polfticas culturales en la economía de mercado: "La cultura no compete sólo a los artistas, científicos y profesores, sino a la vida toda de nuestra sociedad. Debemos liberarnos de las ideologías restrictivas y superar la separación artificial entre nuestra cultura y la cultura mundial. El arte y la literatura no deben ser más objeto de censura, sino contacto libre con el público" (Kreuze, 1990: 21).

La liberación de las ideologias restrictivas de hecho ha supuesto la liberación de un Estado paternal que no debe dirigir la cultura, ni ser el único y nuevo mecenas de toda actividad cultural. Ello es también responsabilidad de los sectores sociales, esto es empresa privada, artistas y consumidores. Como aclara Jungmann, escritor checo: "La cultura se debe acostumbrar a la necesidad de

10. Foro Cívico fue el movimiento político que, agrupando varios parridos, lidero la llamada "Revolución de Terciopelon en noviembre de 1989. 
vivir de los sectores sociales y para ayudarse debe hacerlo ante todo sola y después otros la ayudarán. No puede existir tampoco sin cierto cuidado estatal, esto es un axioma en todo el mundo y ni siquiera aquí se debería poner en duda, porque nadie es ya capaz de sostener la cultura completamente [...]" (Jungmann, 1991: 4).

El documento Cultura y Estado en una sociedad independiente ${ }^{11}$, desarrolla más ampliamente el criterio expresado por Foro Cívico cuando señala: «La tarea principal del Estado en relación con los nuevos valores culturales emergentes ${ }^{12}$, está en dar garantías jurídicas e institucionales a los creadores con libertad. Es decir, la capacidad del hombre de tratar libre y creativamente no debe ser por nadie, ni por nada, tocada.

En la creación de cualquier ley jurídica sobre la cultura es necesario afirmar que el Derecho es un instrumento de las ejecuciones estatales dirigidas a la vida de la sociedad civil, y por eso debe ser utilizado en forma muy cuidadosa. La concepción de nuevos teajustes jurídicos se debe regir por el criterio del papel mínimo del Estado, el cual no interfiere en las bases de la cultura... En vez de proponer leyes especializadas dedicadas a cada parágrafo sobre la cultura, queremos proteger la cultura nacional checa con una legislación que cree un clima económico más favorable, junto a la corrección del sistema fiscal (impuestos)" (Uhde, 1991: 4). O sea, que uno de los primeros y fundamentales aspectos planteados ha sido el de definir los criterios y funciones del Estado con respecto a la cultura, en consonancia con el modelo de economía de mercado. Puesto que en el pasado el Ministerio de Cultura fue una institución típicamente totalitaria, ahora se rescata el principio básico de libertad y autonomía de la cultura con un sistema pluralista, reduciendo la acción del Estado y dejando claro que «la cultura no puede estar sola a merced de las leyes del mercado". El Estado asume ahora el papel de animación e intermediación, además, "el Estado debe globalmente encadenar su relación con la cultura, con los valores y, de esta manera, definir la política cultural» (Kabat, 1993: 3).

Hay que destacar que en la creación y ejecución de políticas culturales en la nueva economía en la República Checa entran en acción en el sector cultural otros sectores sociales marginados en el pasado por el monopolio esratal y partidista de la actividad cultural; tales como la empresa privada nacional y extranjera, los nuevos partidos políticos, grupos religiosos y nuevos sectores de artistas que empiezan a producir nuevos valores simbólicos. Nada más saludable para la cultura que esa pluralidad, en la que el Estado, sin intervenir en la creación, es un dinamizador y en donde el ciudadano tiene las posibilidades de libre elección. Este hecho es muy importante, por cuanto si en el pasa-

11. Me tefiero al documento de Mjlan Uhde, ex-ministro de cultura en $\rfloor_{2}$ República Checa. Noviembre de 1991.

12. A propósito de los nuevos valores, zina de las primeras decisiones en maceria culrural a pocos meses de la "Revolución de Terciopelon (17 de noviembre de 1989), fue la anulación, el cambio y la restitución de los nombres de muchas plazas, parques, calles y estaciones de metro (Praga). Aspecto importante que tiene que ver con la construcción de nuevos valores simbólicos. 
do hubo un proceso de democratización de la cultura, es decir, de creación de una amplia infraestructura con una cobertura para todos los sectores de población, ahora el énfasis es hacia una democracia cultural; es decir, las posibilidades de la libre elección ante la oferta cultural que presentan los creadores, aunque como es obvio, también hay factores de manipulación con las modernas técnicas de publicidad y marketing, o exclusiones con el incremento desmesurado de los precios.

En resumen, las políticas culturales en el nuevo modelo económico pretenden toda una transformación que va desde los niveles de creación, producción, transmisión, distribución y recepción o consumo de bienes simbólicos, hasta la intervención en todas las instancias de los circuitos culturales, esto es, en las de los agentes y los medios de producción, tanto en el sentido del cambio de las relaciones de propiedad, de la base tecnológica, de las formas organizativas, como de los canales de comunicación, de atracción de nuevos públicos y de cambios en las instancias institucionales de organización.

\section{Economía de la cultura en la nueva economía de la República Checa}

Los conceptos principales de economía de la cultura en el nuevo modelo económico en la República Checa parten de considerar que de la dinámica en el proceso de transformación de la economía nacional en economía de mercado, depende la solución de los problemas del desarrollo de la sociedad y que necesariamente deben influenciar en la economía de la cultura. Uno de estos problemas son los recursos financieros escasos, lo cual exige jerarquías en esra fase de transición para toda la economía y el presupuesto estatal y en la que, por supuesto, el sector de la cultura no tendrá el primer lugar ${ }^{13}$. Lo anterior es una tealidad que no admite discusión. Sin embargo, cabe anotar que los recursos estatales en materia cultural siempre serán insuficientes. Aún los países más desarrollados tienen problemas deficitarios y establecen jeratquías distintas al financiamiento prioritario de la cultura. A veces, pareciera que la cultura es más bien una "carga pesada" de complicada responsabilidad, pero de la que se sirven todos los sistemas y sectores sociales. Lo cierto es que la financiación de la cultura en la economía de mercado requiere la participación y responsabilidad de todos los sectores económicos y sociales.

La organización de la actividad económica en el sector cultural en la República Checa (ver nota 1), requiere una alta efectividad en la financiación de gastos y una maximización de ingresos. Por esto se avanza hacia la formación de un fuerte grupo de sujetos de empresa, se privatizan las empresas del Estado - Las más rentables - y se transforman en diferentes tipos de sociedades de negocios - sociedades anónimas, sociedades limitadas, etc. - Éstas deben considerarse como actividades puramente comerciales que intervienen en el mercado cultural. La actividad empresarial más lucrativa en el sector cultural indudablemente es la prioridad en esta fase.

13. Ass lo afirma el suplemento del Ministerio de Cultura, núm. 7, 1991. 
Es evidente que en la economía de mercado el sector cultural es atractivo al nivel de productos que pueden representar un lucro. Es en ellos en los que el capital arriesga una inversión (cine, discos, libros, televisión, radio, etc.), aunque su utilidad pueda ser menor que en el mercado financiero u otro sector industrial. Otro tipo de actividades del sector cultural necesitan soportes diversos, tales como la financiación casi total por el Estado, cuyas partidas son incluidas en los presupuestos oficiales, o cofinanciadas con el apoyo de empresas nacionales y extranjeras, o con aportes de fundaciones que canalizan recursos internacionales, o con ciertos recursos que pueden generar internamente las instituciones culturales. Por eso uno de los nuevos elementos de la nueva economía de la cultura ha sido la de constituir un sistema de recursos en el que juegan papel principal: el fondo estatal, las fundaciones, las instituciones financieras y los patrocinadores privados. Este esquema funciona en todos los países de economía de mercado con formas especiales de incentivos, como los beneficios fiscales para los aportantes.

EI fondo estatal y las fundaciones son formas independientes de canalizar dinero efectivo, el cual puede facilitar préstamos, créditos, subvenciones y puede servir de puente y garantía para préstarnos bancarios únicamente en el sector de la cultura. Los fondos estatales en los países de economía de mercado tienen la característica de no estar sujetos a las restricciones y normas propias de los presupuestos oficiales. Estos recursos, en la esfera de la cultura, pueden ser definidos como capital de riesgo en tanto su fin no es ofrecer recursos no retornables, sino ofrecer garantías para aquellos que prestan dinero para sus proyectos (Uhde, 1991: 6).

Se plantea también que para asegurar la funcionalidad del fondo y las fundaciones, es necesario garantizar su estabilidad financiera a largo plazo. Aspecto obvio que indudablemente requiere formas ágiles de capitalización que pueden ser: oferta de acciones, aportes de empresas con ciertos beneficios fiscales, mecanismos impositivos como el del fondo cinematográfico (cada espectador aporta una corona a la compra de su entrada). También mediante la aseguración y obtención de intereses en cuentas bancarias.

\subsection{El presupuesto}

Como afirma Stiglitz, "[...] el presupuesto es el esqueleto del Estado despojado de toda engañosa ideología. El presupuesto estatal es una especie de escenario donde se registran las fuerzas políticas de la sociedad posindustrial que forcejean por influir en la estructura de asignación de recursos" (Stiglitz, 1988: 20), siendo el sector cultural el que por lo general ha contado con recursos limitados. En la República Checa no hay lugar a dudas y es inevitable que los recursos oficiales para la cultura se resientan con el profundo proceso de cambio; no sólo porque no es considerado sector prioritario, sino porque hay también una lógica económica: si la producción industrial y agrícola decrecen, si el sector servicios luego de un prolongado estancamiento comienza a consolidarse, si hay beneficios fiscales en esta fase para las inversiones y/o nue- 
vas empresas; es obvio que las finanzas del Estado deben estar bastante reducidas, por cuanto la fuente principal de los ingresos del Estado en la economfa de mercado se obtienen de la política fiscal y de algunas empresas estatales manejadas con criterio empresarial. Además, si los gastos eran superiores a los ingresos, es lógico entonces que haya crisis económica.

A lo anterior se agrega la indefinición legislativa e imprecisión en el sector cultural del tipo de instituciones que deben recibir recursos oficiales y cuales no. Además que el Estado ha asumido el control de las instituciones deficitarias y no productivas, porque las empresas rentables en el sector cultural han sido privatizadas (Respekt, 1993: 6), En 1993, para el sector cultural se asignaron 6.300 millones de coronas ( 200 millones de $\$ U S$ aproximadamente) y no cubren los gastos del sector ${ }^{14}$. Además existen otros inconvenientes: la inflación, la carga salarial y los gastos de salud y seguridad social que deben ser cubiertos por el presupuesto (esta estructura presupuestal es la modalidad aplicada en la mayoría de países con economía de mercado).

Por lo general, a causa del desarrollo económico desigual, en las provincias locales el sector cultural cuenta con mayores dificultades y, por supuesto, la Repúblia Checa no es una excepción. La provincia cubre el $70 \%$ de los gastos locales con una destinación incierta y el otro $30 \%$ es aporte nacional. De ahí se deduce que la situación de la cultura financiada por el Estado central estará mejor que la financiada localmente, donde incluso muchas poblaciones no cofiguraron o no elaboraron su presupuesto definitivo para 1993. (Respekt, 1993: 6). En las economías de mercado, el patrocinio cultural complementa con un porcentaje muy significativo los gastos del sector cultural y en la República checa es un aspecto que ahora empieza a desarrollarse.

Finalmente, para 1993, si comparamos los presupuestos de España (83.000 millones de pesetas, aproximadamente 16.600 millones de coronas) con el de la República Checa (6.300 millones de Kc.) y los distribuimos entre los volúmenes de población respectivos (España $=40$ millones de habitantes. República Checa $=10$ millones), concluiremos que la República Checa destina $630 \mathrm{kc}$. por habitante y España $518.75 \mathrm{Kc}$. O sea, que los recursos oficiales destinados a la cultura en la República Checa no son tan bajos. El problema es que el desarrollo de los sectores independientes (empresa privada) -que en España y el resto de países de economía de mercado cumplen un papel complementario importante para el sector cultural por los gasros que destinan a cultura - aún no se ha potenciado en el Este en general. De ahí la importancia de la animación que promueva el Estado y la sociedad civil en el proceso.

\subsection{Las privatizaciones en el sector cultural}

En el Este, en general, y en la República Checa, en particular, el proceso de privatización es el aspecto central de la transición a la economía de mercado,

14. Es una limitación que la información haya sido insuficiente para un mayor análisis, pero el hermetismo oficial lo imposibilitó. 
incluyendo por supuesto al sector cultural. Es muy evidente que el proceso debe ofrecer garantías de rentabilidad o, por lo menos, buenas expectativas para la inversión. Luego, la lógica no podía ser otra que la de privatizar las empresas de la industria de la cultura autofinanciables en el modelo anterior (editoriales, cine, vídeo, discográficas, circos y variedades, cerámica, etc.). La modalidad principal ha sido la de constituir sociedades anónimas ${ }^{15}$. El Estado

15. Comentario especial merece la modalidad de la gran privatización, definida principalmente en las sociedades anónimas (S.A.). Modelo de privatizacion que ha sido presentado como la manera más democrática del proceso de transformación de las grandes empresas en rodo el Este y en particular en Checoslovaquia, mediante los fondos de privatización dirigidos por especialistas que deciden las inversiones con los recursos caprados de la población. Sí bien las S.A. representan una forma de participación variada de capital, expresada en acciones, también es cierto que este tipo de empresas, como ensefia la historia en las economias de mercado, han mostrado diversos problemas que han afecrado coda la estructura economi$\mathrm{ca}-\mathrm{y}$ las lecciones de la historia no deben tomarse con ligereza, ni sin cuestionamientoe, incluso, se habla de su tendencia autodestructiva con el boom de fusiones y adquisiciones de empresas en la década de los ochenta. Boom que lievo a la bancarrota de muchas empresas que luego exigian la intervención del Estado para financiarlas, originando serios desequilibrios fiscales. Individualizacion de las utilidades y socialización de las perdidas, es una frase perfecta que resume esta situación.

Varios son los elementos que sustentan las anomalias que pueden presentar las sociedades anónimas:

a) El argumento de estrucrua democrática de propiedad queda en tela de juicio, porque el poder lo ejercen los grupos que poseen el mayor número de acciones y quien ejerce el poder efectivo es la direccion de la S.A., porque los accionistas son numerosos y dispersos y los vocos individuales cuentan muy poco. Además el accionista no posee los conocimientos requeridos para intervenir en los diversos y complejos asuntos de las empresas. Es en la dirección donde descansa la autoridad.

b) En la doctrina económica, es casi verdad reológica que el objerivo de roda empresa es maximizar sus beneficios a propietarios, accionistas y capitalistas. Esta teoría se incorpora tanto en el supuesto de la maximización implacable del beneficio como la rendición desinteresada de las ganancias resultantes por parte de los responsables de la maximización. Y, en realidad, el supuesto de la persecución del propio interés es válido, pero en cuanto gerentes y directivos han escapado al control de los accionistas, han pasado a maximizar crecienremente sus propios benefictos. Por ejemplo, en los Estados Unidos, los directivos de las 300 empresas más grandes del país, en 1980 tenían ingresos 29 veces más altos que los del trabajador industrial medio, 10 años más tarde esos mismos directivos tenian ingresos 93 veces mayores (Galbraith, 1922: 66).

Tenia razón Adam Smith cuando se oponia a las sociedades anónimas y a las grandes empresas que hoy dominan corporaciones, afirmando: "De los directores de estas empresas... siendo administradores más bien del dinero ajeno que del suyo propio, no se puede en realidad esperar que lo controlen y administren con la misma atención constante con que los socios de una sociedad limitada suelen controlat su propio dinero... En consecuencia, prevalecerán siempre la negligencia y el derroche, en mayor 0 menor grado, en la gestión de los modernos negocios de una empresa de ese génerow.

c) Las fusiones y adquisiciones, por lo general, no pasan sin beneftcio de inventario con recompensas a las direcciones que son quienes preparan los procesos. Este fenómeno ha traído efectos negarivos para la industria productiva no sólo en América Latina y los Estados Unidos, sino tambien en Europa.

d) La rapina de fusiones $y$ adquisiciones creó una ola especulativa, por ejemplo a nivel inmobiliario, sobre todo en las superficies comerciales, en condominios, originando grandes operaciones bancarias a veces incontroladas, como sucedio en América Latina, 
mantiene aún el control de algunas empresas que considera de interés público mediante las llamadas acciones de oro, las cuales no producen oro alguno, pero, para evitar "especulaciones», le dan al Estado el derecho exclusivo a decidir que la empresa no puede abandonar la esfera de actividad y/o vender o alquilar el inmobiliario. Entre ellas figuran Lucerna Films, Kino Technika, Vuzort, Estudios de cine Barrandov, Albatros (Respekt, 1993: 6). Considero muy positiva esta acción del Estado, mientras no intervenga en la creación, por cuanto es una garantía oficial no sólo frente a posibles descalabros de los inversores, sino que también puede evitar "turbios" negocios.

En el sector cultural también se han escuchado voces inconformes acerca de los procedimientos en la privatización de las empresas. Se argumentan privilegios de información y carencia de ética para las asignaciones (caso Estudios de Cine Barrandov, Supraphon), aunque no se hacen declaraciones públicas ${ }^{16}$. Es quimérico y lamentable que el sector cultural, siendo un potencial simbólico, no haya aprovechado este proceso para mostrar de cara a la ciudadanía checa, que es posible un cambio con transparencia y un nuevo modelo ético (la gran catencia del mundo actual). Desperdicia la posibilidad de informar públicamente con cifras los procesos de negociación. Teoricamente son actos públicos cuya información no tiene porqué ser restringida y sí menoscaba la joven democracia.

Para la radio, informaba el ex-ministro Uhde que en 1991 se habían concedido treinta licencias privadas. O sea, se amplio la oferta radial, hecho muy positivo para los gustos del público y la ampliación de la oferta cultural. En Praga, y tan sólo en dos años, las estaciones de FM han pasado de tres, antes de los cambios, a diecinueve actualmente. En lo que respecta al sector privado en otras áreas como la actividad editorial, en 1990 y hasta octubre de 1991, se habían concedido cuatro mil licencias por el Ministerio de Cultura. Actividad que ha tenido un repunte muy próspero, luego de los numerosos comentarios acerca de la "bancarrota» de la anterior red estatal de distribución (Respekt, 7 , 1993: 6).

En 1991, el ministro Uhde informó de la abolición de la ley de nacionalización de la cinematografía que data de 1945 , y anunció la distribución y exhibición por empresas privadas; además, advertía del decaimiento de la producción que favorecería la presencia del cine norteamericano (Uhde, 1991: 8). En efec-

los Estados Unidos y algunos países de Europa terminando en errores graves del sector bancarto, cometidos habitualmente con los préstamos mayores y por los direcrivos más alcos, cuyas consecuencias fueron mayores flujos económicos y desplazamiento ficticio de recursos. (Galbraith, 1992: 69)

La pregunta es: ¿Puede suceder todo lo ancerior en un país que, como Checoslovaquia, carece de experiencia en este terreno y desconoce mucho la información que ha denunciado estas bancartotas? En el campo de las sociedades anónimas, la acción de la economfa pública es importante para el control y, finalmente, es el Estado quien puede y debe ejercerlo eficazmente.

16. Escos aspectos han sido informaciones obtenidas por el autor de este trabajo. 
to, un breve recuento aleatorio mensual del número de programaciones (repitiendo las películas) en las salas de cine en Praga, arrojó el siguiente resultado:

Tabla 8. Progtamación de películas en salas de cine de Praga

\begin{tabular}{llclll}
\hline Fecha & $\begin{array}{l}\text { Total } \\
\text { programas }\end{array}$ & $\begin{array}{l}\text { Películas } \\
\text { americanas }\end{array}$ & $\begin{array}{l}\text { Películas } \\
\text { europeas }\end{array}$ & $\begin{array}{l}\text { República } \\
\text { Checa }\end{array}$ & Otros \\
\hline Abril 1990 & 276 & 92 & 60 & 109 & 16 \\
Abril 1991 & 175 & 79 & 49 & 34 & 13 \\
Febrero 1993 & 257 & 151 & 30 & 60 & 16 \\
\hline
\end{tabular}

Funente: Elaborado por el auror de este trabajo en base a Kulturní Prehled (programa cultural).

En abril de 1992, de once películas extranjeras anunciadas como estreno, nueve eran estadounidenses y dos eran francesas. En enero de 1993, de diez películas de estreno, nueve eran estadounidenses y una era francesa. No es nada distinto de lo que acontece en Europa y el mundo. Sencillamente, la República Checa ha ingresado al "club» de distribuidores, exhibidores y consumidores del cine norteamericano que, obviamente, es más rentable y es del gusto de los grandes públicos. Además, se supone que debe generar un ingreso considerable al Estado en concepto de impuestos.

En el sector del vídeo y producciones audiovisuales, en cuanto a intermediarios y agencias, se concedieron hasta octubre de 1991, 300 licencias (documento núm. 14.104/91 60/v/1 del Ministerio de Cultura). Un hecho destacable de la dinámica empresarial es que ha permitido la absorción de 2.000 a 4.000 puestos oficiales, lo que ha suplido en parte las necesidades de empleo ante la reducción del número de empleados en el sector oficial de la cultura.

Indudablemente, la privatización en el sector cultural ha ampliado enormemente la oferta cultural, y no sólo eso, sino que ha generado una democracia cultural, por supuesto influenciada por la publicidad, que cumple los propósitos del nuevo mercado simbólico en el proceso de inducir las preferencias y, de paso, intoxicar el ambiente visual del entorno en la República Checa ${ }^{17}$. Resulta, entonces, inocente la apreciación del escritor Milan Jungmann, cuando afirmaba que un hecho negativo de los cambios es la publicidad que florece y la cual espera que sólo sea transitoria (Jungmann, 1991: 4). Todo lo contrario, es y será mayot e implacable.

\section{Perspectivas de las políticas culturales en la República Checa}

En base a lo desarrollado en este trabajo, considero que hablar de las perspectivas culturales en la República Checa puede resultar un tanto subjetivo

17. Nada más desagradable que el caballo de Marlboro o el álido camello «antiecolbgicon de Cámel, los cuales han invadido las ciudades y no hay respiro visual que rectee el transeúnte. Es ałgo más que una invasión cultural. Es un insulto. 
y superficial debido a la escasa información con que he contado, sobre todo por la generalidad de las cifras y opiniones utilizadas que son las que públicamente se conocen. Sin embargo, es posible señalar algunos rasgos y recomendaciones que, dentro de la lógica de la economía de mercado, son previsibles:

- La infraestructura cultural creada en la República Checa es muy diversa y amplia. Si bien se utilizó en el pasado, el oficialismo y la unidimensionalidad de la oferta cultural generaron su infrautilizacion. La existencia de esta infraestructura es, indudablemente, atractiva para la inversión privada. Además, con estrategias de sector es posible reactivar y sin duda incrementar la oferta y la demanda. Ello exige esfuerzos oficiales y privados para la creación de soportes mixtos. Como afirma Galbraith: "[...] la economía moderna, con su combinación de incentivos de mercado e intervención pública, ha demostrado un vigor excepcional [...] La maravilla de la economía mixta moderna es su fuerza interior potencial y la capacidad consiguiente que tiene. A menudo puede superar la incapacidad, el error, la indiferencia o la grave ignorancia de aquellos a los que se considera responsables de su funcionamiento" (Galbraith, 1992: 182).

- Sería un grave error mirar el mercado o las privatizaciones como las simples "soluciones salomónicas", porque el mercado y la propiedad son mecanismos, unos medios y no fines o principios máximos de gestión. Para el sector cultural, la agudeza está más en concitar el interés de todos los sectores sociales para desarrollar esa economía mixta en la que el Estado tiene una altísima responsabilidad como garante de la transición. Hay que establecer un punto de convergencia, de equilibrio si se quiere, entre el interés público y el interés privado.

- El alto porencial de consumo de la sociedad checa, explicado por años de restricción, sobre todo en bienes y servicios de consumo, es un fenómeno "positivo", pero a la vez condicionado por los avances de la economía de mercado y las posibilidades reales de la capacidad adquisitiva de la población, la que indudablemente avanzará hacia diferenciaciones sociales que llegarán a extremos. Eso debe estar muy claro, sobre todo en los círculos oficiales, porque es el Estado quien debe intervenir como regulador y gestor de políticas redistributivas, para eso sirven las políticas fiscales. Ese ambiente de aceptación de la acción del Estado debe generarla él mismo $y$, desde el punto de vista cultural, tiene que ver con la creación de nuevos valores simbólicos, donde el mercado tiene los mismos límites de acción que el Estado ${ }^{18}$.

- Es de prever un cambio en los consumos y hábitos culturales con la ampliación de la oferta e incremento de la demanda de productos culturales (libros,

18. Los niveles de consumo no se moverán por el principio de la necesidad, sino que el deseo privado siempre es desmesurado y su hedonismo es destructor de las necesidades sociales. 
discos, vídeos, televisores, computadores, juegos electrónicos, cultura del ocio), los cuales influirán en la demanda de servicios culturales tradicionales (cine, teatro, conciertos, etc.). Podemos decir que la demanda puede tender al aislamiento, esto es, a concentrarse en los hogares. De ahí la gran importancia de políticas culturales sectoriales y en los medios de comunicación que deben ampliar la oferta de programación y servir al mismo tiempo de soporte a las expresiones tradicionales. Ello supone también que los sectores tradicionales de acción cultural deben hacer un esfuerzo por renovar los ambientes, haciéndolos más acogedores, vivos y atractivos.

- El hecho de la ampliación de la libertad supone que habrá de seguro un incremento de la creación artística, con la correspondiente proyección de nuevas propuestas estéticas. La República Checa posee una red no sólo de formación, sino que cuenta con la infraestructura para relacionar esa creación con el público. Es aquí donde considero que cobra importancia el desarrollo de la economía mixta, por cuanto es claro que la formación artística exige grandes recursos financieros y proyección de largo plazo. También la economía de mercado requiere en el sector cultural nuevas formas de instrucción para el éxito comercial de las producciones culturales, esto es, en áreas de dirección, gestión, promoción y marketing.

- Un hecho real es que la industria cultural produce dividendos sustanciales que en la República Checa habrán de ser cuantificados con más precisión. Por lo general, la participación de las compañías extranjeras supone la exportación de divisas $y$, a veces, sin reinversión. Esto es un aspecto importante a tener en cuenta para el ofrecimiento de beneficios fiscales que estimulen la inversión en el sector cultural.

- La planificación cultural en el nuevo modelo económico no supone la pérdida de su vigencia, más bien al contrario, es uno de los elementos rescatables del viejo sistema y que la economía de mercado ha puesto en práctica, luego de mirarlo con recelo. Paralelo al desarrollo de la industria cultural, también se desarrolla con fuerza una producción cultural aficionada. Es decir, todos los ciudadanos son y pueden ser un productor cultural independiente y colectivo. La existencia de esta producción propia de la sociedad civil crea sus formas organizativas, clubes, asociaciones, fundaciones, etc. y también sus formas de distribución y consumo, formando sus propios públicos o consumidores. Son parte de la expresión de la democracia cultural a tener en cuenta en su promoción y desarrollo, pero, por lo general, escapan a los intentos planificadores.

Finalmente, debo reiterar que toda acción de la economía pública, particularmente en el sector cultural, está basada en la voluntad política, entre otros aspectos, y además apoyada en la información transparente que utilice, pilar además de las estadísticas. Sin embargo, el secretismo de algunos sectores puede imposibilitar la elaboración de datos fiables, tanto para trabajos de investigación como para la definición de políticas. Esta carencia puede agravarse con el proceso de crecimiento de los sectores privados y su recelo informativo. 
Dicha desconfianza, presente también en los sectores oficiales, plantea la urgencia de reevaluar las actividades de los departamentos de estadística de las instituciones oficiales y la necesidad de generar procesos de reeducación. Todos los sectores, tanto el estatal como la empresa privada y la sociedad civil, necesitan de este soporte importante de la economfa de la cultura.

\section{Bibliografía}

Generalitat de Catalunya, Departament de Cultura (1991). Estructura del sector teatral a Catalunya. Barcelona.

CerP, Martín; KADERABKOVA, D. (1986). Rozvoj Odvetvt Kultury. Ustav pro Vyzkum Kultury. Praga.

DUBCEK, Alexander (1988). "Veinte años después de 1968». Revista Rto Arte. Afio 1. núm. 1. Río de Janeiro

El Pats, suplemento Domingo. Madrid, 3 de enero de 1993.

- Sección Negocios. Madrid, 5 de agosto de 1990.

- Sección Negocios. Madrid, 6 de noviembre de 1992.

Flegel, Vladimir (1974). "Ustava Ceskosłovenské Soc. Rep.» 1 I de julio de 1960. Praga: Orbis.

GalbRatTH, Kenneth (1992). La cultura de la satisfacción. Ariel Sociedad Ec. Barcelona.

HAMERNIKOVA, B. (1989). Ekonomika nevyrobni Sfery: Socialne Ekonomické aspekty kultury. Praga: SNTL.

JunGmanN, Milan. «Konec Kultu Kultury». Mlada Fronta. Praga, 18 de marzo de 1991. KABAT, Jindrich. «Penize versus Kultury". Vecerni Praba. Praga, 3 de marzo de 1993. KATOUZIAN, Homayun (1982). Ideologia y metodo en economia. Madrid: H. Blume ediciones.

KosiK, Karel (1988), “La crisis del hombre contemporáneon. Revista Rio Arte. Año 1. núm. 1, Río de Janeiro.

Krevze, Enrique. "Diario de Praga". Revista Vuelta. Año XIV. núm. 158. México, enero de 1990.

MAREK, Miroslav y otros (1977). Poltticas culturales en Checoslovaquia. UNESCO, 2a. ed. París.

Ministerio de Cultura de la Republica Checa (1991). "Suplemento núm. 7\%. Praga.

Ministerio de Cultura de España (1982). El Cine y el Estado. Madrid. (Colección Cultura y Comercio, núm. 20).

Respekt, núm. 7. Praga, 1993.

SBIRKA Zakonu, (1993). Ceske Republiky Rocnik. Ustav Ceské Republiky. Praga, 1993.

Stiglitz, J.; AtKinso, A. (1988). Lecciones sobre Economía Pública. Ministerio de Economía y Hacienda (IEF). Madrid.

UhDe, Milan (1991). Kultura a Stát ve svobodné spolecnosti. Minisrr. Kulturury, Praga.

UNESCO, Comision National Finnish (1980). The development of cultural policies in Europe, núm. 21. Helsinki.

UNESCO, ThENEVIN, P. (1974). Pour une methodologie de la planification culturelle. París. 